\title{
A methodology for the risk assessment of climate variability and change under uncertainty. A case study: coffee production in Veracruz, Mexico
}

\author{
Francisco Estrada $\cdot$ Carlos Gay $\cdot$ Cecilia Conde
}

Received: 20 December 2008/Accepted: 3 October 2011 /Published online: 22 December 2011

C The Author(s) 2011. This article is published with open access at Springerlink.com

\begin{abstract}
Existing methods for the assessment of the potential impacts of climate change in productive activities and sectors are usually limited to point estimates that do not consider the inherent variability and uncertainty of climatic and socioeconomic variables. This is a major drawback given that only a limited and potentially misleading estimation of risk can be expected when ignoring such determinant factors. In this paper, a new methodology is introduced that is capable of integrating the agent's beliefs and expert judgment into the assessment of the potential impacts of climate change in a quantitative manner by means of an objective procedure. The goal is to produce tailor-made information to assist decision-making under uncertainty in a way that is consistent with the current state of knowledge and the available subjective "expert" information. Time-charts of the evolution of different risk measures, that can be relevant for assisting decision-making and planning, can be constructed using this new methodology. This methodology is illustrated with a case study of coffee production in Mexico. Time-dependent probabilistic scenarios for coffee production and income, conditional on the agent's beliefs and expert judgment, are developed for the average producer under uncertain future conditions. It is shown that variability in production and income, generated by introducing climate variability and uncertainty are important factors affecting decision-making and the assessment of economic viability that are frequently ignored. The concept of Value at Risk, commonly applied in financial risk management, is introduced as a means for estimating the maximum expected loss for a previously chosen confidence level. Results are tailor-made for agents that have incomplete information and different beliefs. In this case study, the costs of climate change for coffee production in Veracruz are estimated to have a present value representing from 3 to 14 times the current annual value of coffee production in the state.
\end{abstract}

F. Estrada $(\bowtie) \cdot$ C. Gay $\cdot$ C. Conde

Centro de Ciencias de la Atmósfera, Universidad Nacional Autónoma de México (UNAM), Ciudad Universitaria, Circuito Exterior, 0451 Mexico, DF, Mexico

e-mail: feporrua@atmosfera.unam.mx

F. Estrada

Institute for Environmental Studies, Vrije Universiteit, Amsterdam, Netherlands 


\section{Introduction}

Since the late 1990s important advances have taken place in the development of methodologies for estimating the potential impacts of climate change on human and natural systems. The standard approach of climate scenario-driven impact studies has been expanded to a range of different approaches such as the assessment of current and future adaptation capacity, social vulnerability and policy, among others (Carter et al. 2007).

The Fourth Assessment Report (AR4, WGII-IPCC 2007; Carter, et al., 2007) briefly reviews the new assessment methods for climate change impact, adaptation and vulnerability (CCIAV). The IPCC distinguishes five approaches for CCIAV, four of them are considered conventional: impact assessment, adaptation assessment, vulnerability assessment and, integrated assessment. The fifth approach, risk management, has evolved as the CCIAV studies have begun to be used in mainstream policy-making (Carter et al., 2007). These studies are oriented towards decision-making activities such as planning, management and policy-making, and are suitable for a wide range of scales: from global to local and from sector to case study.

The development of models that combine physical and socioeconomic determinants has also been of particular importance since it has allowed the integrated assessment of potential impacts, providing more realistic estimations that consider multiple stressors. Nevertheless, some other issues like uncertainty and variability are still pervasive in CCIAV studies, and there is a lack of methodologies to formally address these issues. For example, even in the UNFCCC's Compendium on methods and tools to evaluate impacts of, and vulnerability to, climate change (UNFCCC 2008A) there are few methods that integrate uncertainty and variability in their estimations.

Most of the current assessments of the potential impacts of climate change have been carried out using methodologies that do not allow the inclusion of the variability and uncertainty inherent to climate and socioeconomic variables. In consequence, such methodologies can only provide a very limited (and potentially biased) assessment of the risk that the systems in study would face under climate change conditions, and are based on a single realization of a combination of different stochastic processes.

In the AR4, the Working Group II of the IPCC stresses the importance of producing new methods to address uncertainty in climate change studies in order to inform decisionmaking under uncertainty, and provides examples of studies that have suggested methods to do this (see for example, Toth et al. 2003a, b; Jones 2001; Willows and Connell 2003; UNDP, 2005; more recent studies include, for example, Tebaldi and Lobell 2008).

The methodology proposed in this paper builds on the risk management framework and aims to inform decision-making under uncertainty by producing probabilistic assessments of the potential impacts of climate change that: consider the uncertainty in climate and socioeconomic variables as well as their inherent variability; promote stakeholder involvement by including their subjective information and; produce tailor-made risk measures as well as estimations of the date to reach critical thresholds defined by the stakeholder.

\subsection{Uncertainty in climate scenarios}

In recent years, advances in the understanding and modeling of the climate system have permitted to increase the confidence in, and the complexity of, climate models as well as to further improve the space and time resolution of climate change scenarios (IPCC-WGI 2007). There is now the possibility of estimating uncertainty ranges for the future climate at 
global and regional levels and of constructing probabilistic climate change scenarios using different storylines and models (Meehl et al. 2007; Christensen et al. 2007).

Unfortunately, due to the lack of appropriate methodologies for handling uncertainty in climate change scenarios, a large portion of the available information is being poorly exploited for CCIAV and therefore, climate change science is failing to fully accomplish one of its main objectives: assisting decision-making and promoting optimal or "best response" decision-making.

The vast majority of the literature on impact assessment is based on recommendations such as using at least two climate change scenarios (the highest and lowest or those corresponding to two development scenarios that, based on "expert" subjective information, are thought to be most likely) for addressing uncertainty in climate projections (UNFCCC $2008 \mathrm{a}, \mathrm{b})$. This is one of the most common recommendations that have been used in important large-scale studies such as National Communications (see for example, Gobierno de la República de Argentina 2008; Secretaría de Medio Ambiente y Recursos Naturales/ Instituto Nacional de Ecología 2006; Government of Japan 2006; Government of the Federal Republic of Germany 2006). Nevertheless, results following these recommendations are usually hard to interpret, provide no measure of the probability of the different outcomes, are difficult for communicating risk to stakeholders and decision-makers, and do not make full use of the available information/uncertainty.

Since over a decade, new methodologies for impact assessment (including those that use of Monte Carlo simulation) that are more suitable for dealing with uncertainty have been developed and implemented (see for example, Titus and Narayanan 1996; Yohe and Schlesinger 1998; Jones 2000; New and Hulme 2000; Preston 2006; Nawaz and Adeloye 2006; Gay et al. 2006c). These methodologies can take advantage of the recently available possibility of constructing probabilistic climate change scenarios but greatly depend on the assumptions needed to express uncertainty in terms of a probability distribution. One of the major pitfalls is that these assumptions (probability distributions) are commonly presented as "objective" facts because they are based on a frequentist approach, when it should be clearly stated that they are all subjective representations of beliefs (Moss and Schneider 2000; Ahmad and Warrick 2001; Gay and Estrada 2010). Subjective beliefs should be brought forward, be clearly stated, and probability distributions should be a meaningful expression of the decisionmaker beliefs and not some impersonal, one-size fits all, statistically inadequate device.

Dealing with uncertainty in climate change scenarios has become an issue of intense debate in the scientific community (Schneider 2001, 2002; Allen 2003; Pittock et al. 2001; Grübler and Nakicenovic 2001; IPCC-WGI, 2007; for example) that has lead to the proposal of different methods. The contribution of the Working Group I (WGI) to the IPCC's AR4 provides a review of some of the advances that have taken place in the last decade regarding probabilistic scenarios and uncertainty management.

In the AR4, the WGI takes on the issue of trying to assess model uncertainty and provides best estimates or multi-model averages, likely ranges, as well as other types of probabilistic scenarios for the six marker scenarios included in the Special Report on Emissions Scenarios (SRES, Nakicenovic et al. 2000). Some of the shortcomings of the approaches included in the WGI contribution to the AR4 for producing probabilistic climate change scenarios have been discussed by the authors in a previous paper (Gay and Estrada 2010). We believe that one of the basic problems is that, in general, the approaches proposed are based on forecast methodologies. These methodologies are designed to address aleatory uncertainty and not epistemic uncertainty, which is dominant in climate change scenarios. In this manner, forecast methodologies cannot resolve epistemic uncertainty and therefore they may not be adequate for supporting decision-making. 
Furthermore, the IPCC keeps avoiding the emissions uncertainty and therefore, these probabilistic scenarios are conditional on the emission scenario for which we have no information regarding its probability of occurrence. Consequently, decision-makers are left to again only with probability estimates that are conditional on something for which probabilities of occurrence have not been assigned, to carry on with their responsibilities. Clearly, these estimates are of very limited practical interest for decision-making.

Other methods that have become popular are based on weighting models accordingly to their accuracy reproducing observed climate (see for example, IPCC-TGICA 1999; 2007; Wigley 2008, Carter et al., 2007). This type of methods might provide important information which might be used to reduce uncertainty. Nevertheless, there is no guarantee that the models that provide an accurate representation of the current climate will continue to do so in the future, and therefore this method could lead to trading uncertainty by ignorance (Schneider 2003). Also, the diversity of models could be at stake, and models could become less and less independent (Allen 2003).

All these methodologies represent important advances towards making climate change science increasingly useful for decision-making. Nevertheless, all of them still greatly dismiss uncertainty and therefore do not provide an adequate representation of the current state of knowledge in climate modeling. It is important to realize that the complexity of the problem ensures that the available information for decision-making will always be incomplete and that therefore scientific or objective information will have to be complemented with subjective expert information. As discussed by the authors in a previous paper (Gay and Estrada 2010), objective probabilities in climate change scenarios are not attainable and therefore no "true or objective" impact scenario can be constructed, even in a probabilistic framework.

This paper uses the methodology for constructing probabilistic climate change scenarios, based on the Maximum Entropy Principle and proposed in Gay and Estrada (2010). These estimates have desirable properties such as: they are the least biased estimate possible on the available information; maximize the uncertainty (entropy) subject to the partial information that is given; the maximum entropy distribution assigns a positive probability to every event that is not excluded by the given information; no quantifiable possibility is ignored. The probabilities obtained in this manner are the best predictions possible with the state of knowledge and subjective information that is available.

\subsection{Natural climate variability}

Estimations regarding how climate variability could evolve under climate change conditions are commonly based on simulations from physical climate models (General Circulation Models, for example). The two main approaches are based on performing basic statistical analysis on one single run or on ensembles of runs of the same climate model.

For example, the document Handling Uncertainties of UK Climate Impacts Programme ${ }^{1}$ recommends estimating future climate variability by creating an ensemble of three simulations of the same model under the same emissions scenario and parameterizations but with slightly different initial conditions. The variability shown by these simulations is assumed to adequately represent natural climate variability under a particular climate change scenario. On the other hand, the MAGICC-SCENGEN software (developed by the Climate Research Unit and the National Center for Atmospheric Research, Wigley 1994, 2003, 2008; Hulme et al. 2000), which is widely used for investigating future climate change at

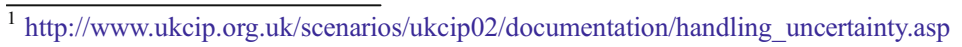


global and regional levels, uses 20-year samples for calculating the standard deviations of single simulations for approximating future climate variability (Wigley 1994, 2008).

Both approaches have important drawbacks. On the one hand, although the ability of climate models for simulating the climate system at global and regional scales has greatly improved, climate models are currently not able to entirely reproduce observed climate variability (Meehl et al. 2007; Christensen et al. 2007). In addition, using a limited number of model runs (three, for example) will hardly produce an adequate representation of even the model's internal variability, much less will it provide an approximation of present, and even worse, of future natural climate variability.

On the other hand, using fixed sample sizes (20 years in the case of the MAGICCSCENGEN software) of climate model simulations - or for that matter, observed sub-samples of 30 years (WMO 1983) - for estimating climate variability will clearly produce deficient estimations. There are two main reasons for this argument: first, by definition, under climate change, climate variables will be (are) non-stationary processes, so if the time-series properties of these processes are not considered for any statistical analysis (even for calculating a simple standard deviation), they are very likely to lead us to find spurious changes in the moments of their distributions (Gay et al. 2007). In this case, climate variability could be wrongly thought to be time-dependent and therefore could be expected to increase (decrease) in the future, producing poor estimations of potential future climate risk. In this case, limiting sample size to 20,30 or to any fixed number or years (as is currently done and recommended by the WMO) will still produce inadequate estimations of climate variability. Second, if the process turns out to be stationary, limiting the sample size to a subsample of the available data will only produce inefficient estimations of its variability.

Recent studies (Gay et al. 2007; 2009; Estrada et al. 2010; IPCC-WGI, 2007) suggest that climate change will possibly manifest as a change-in-the-mean of (some) climate variables, without altering other distribution moments, at least in the case of monthly and annual means.

For these reasons, it is proposed that the best estimation of future climate variability (with the available information) is the best possible estimation of current natural variability, given that it also provides information of how climate variables have responded to current observed climate change. For this purpose, in this paper statistically adequate time-series models ${ }^{2}$ will be estimated to infer the data generating processes.

\section{Methodology description and simulation procedures}

The simulation methodology presented here considers two possible alternatives for generating probabilistic scenarios of the potential impacts: a) static, which generates a potential impact distribution for a particular time horizon (for example 2020 or 2050) and; b) dynamic, which provides the evolution of the potential impacts' distribution over a time period (present time to 2050, for example). The methodology for both alternatives can be described in the following steps:

1) Define potential input and output variables for model and simulation.

2) Build a statistically adequate model for the dependent variable being simulated (i.e. the activity or sector under study). This simulation methodology could also be applied to

\footnotetext{
${ }^{2}$ A statistically adequate model satisfies its probabilistic assumptions. As such, a it ensures "the empirical validity of the probabilistic assumptions underlying a statistical model" (Spanos and Mcguirk 2002; Andreou and Spanos, 2003). Statistical adequacy provides a sufficient condition for statistical inference because it presupposes the validity of the model specification assumptions (Andreou and Spanos, 2003).
} 
other types of models such as physically based crops simulators, water-balance models or any other type of model that can be adapted for producing a large number of simulations.

3) Obtain a comprehensive range of climate change scenarios for each of the climate variables used as input variables for simulation. Obtain, as well, future scenarios for the non-climate variables included as input variables.

4) Obtain the maximum entropy distributions for climate and non-climate variables. For this step, it is required to choose an arbitrarily mean average change. As described in Gay and Estrada (2010), two main approaches can be used for selecting this arbitrary average value:

a) The first approach makes use of the agent's attitude towards uncertainty (see, for example, Mukerji 2000; Kelsey and Eichberger 2009; Stein and Segal 2006; Wakker 2001). When decisions are to be taken under subjective, deep or epistemic uncertainty, the decision-maker has limited knowledge or information to assign probabilities to the various possible outcomes. As stated by Ellsberg (1961) "what is at issue might be called the ambiguity of this information, a quality depending on the amount, type, reliability and "unanimity" of information, and giving rise to one's degree of "confidence" in an estimate of relative likelihoods" .3. In this case a uncertainty averse or ambiguity averse decision maker adjusts his probability distribution on the side of caution in response to his imprecise knowledge of the odds (Mukerji 2000). In Gay and Estrada (2010) three types of attitudes towards uncertainty are used: cautious, neutral and reckless.

The term cautious agent is used for those agents that when facing an uncertain situation will assign a higher subjective probability of occurrence to the least favorable outcomes than a neutral agent would. This type of decision-maker will chose a higher average mean change than the central value of the distribution (defined as the sum of the lowest and highest values divided by two). A neutral decision-maker would choose a uniform distribution which is a maximum entropy distribution in the absence of additional information; his attitude towards uncertainty does not lead him to assign higher or lower weights to any possible outcome. In such manner he will chose the central value of the distribution as the average mean change. A reckless decision-maker will tend to select a lower average mean change than the central value of the distribution, assigning lower probability of occurrence to the least favorable outcomes, showing a lower level of concern for the possibility of underestimating the probabilities of occurrence of these outcomes.

b) The second approach consists in choosing "high" and "low" average change values, as is currently recommended for other methodologies used for impact assessment.

The relative entropy and the information index can be used to keep track of how much the probability assignment depends on the included subjective information.

5) Build statistically adequate time-series models in order to infer the properties of the data generating processes of the input variables. With this information, produce

\footnotetext{
${ }^{3}$ Ellsberg (1961) distinguishes between situations when the decision-maker: 1) lacks of any information whatsoever ("complete ignorance") in which rules such as minimaxing, maximaxing, Hurwicz criteria or minimaxing regret are adequate; 2) has enough information to assign a definite and precise probability distribution. In this case the "Savage axioms, and the general "Bayesian" approach, are unquestionably appropriate ... his uncertainty in such a situation is unequivocally in the form of "risk"." and; 3) a state of information in which the problem cannot be characterized as ignorance or risk and falls in what is called "Knightian", deep or epistemic uncertainty. This is when ambiguity arises, and we believe that this is the case of probabilistic climate change scenarios.
} 
stationary time-series of these variables and find the probability distribution that provides the best fit. Look for possible correlation among input variables. ${ }^{4}$ For other input variables for which information is not available or is judged to be nonrepresentative of their future evolution, choose non-informative probability distributions such as uniform, for example. Recall that a uniform distribution is a maximum entropy distribution when no additional information is available.

6) a) If the objective is to generate a realization for a given year (2050, for example) proceed as follows. Generate a random number from one of the maximum entropy distributions found in step 4, and use it as the mean of the corresponding probability distribution found in step 5. Generate a realization form this distribution. Repeat for each variable. b) If the objective is to generate a dynamic simulation for a time period of length $n$ such that $t=1,2, \ldots, n$, proceed as follows. Generate a realization from the maximum entropy distribution and divide it by $n$ (the length of the time period). This will be the slope of a linear trend of length $n$. Generate random numbers from the probability distribution found in step 5; generate a realization of size $\mathrm{n}$ of the data generating process (white noise, autoregressive (AR), moving averages (MA), ARMA, etc.) and add it to the linear trend. Repeat for every variable.

7) Define the evolution of the uncertainty in variables represented with non-informative distributions. For example, it could be reasonable to represent our increasing uncertainty regarding the value that a price variable could take in the future by means of a uniform distribution with a time-dependent support. Repeat for every variable for which information is not available or is judged to be non-representative of their future evolution.

8) Introduce these simulations as input variables in the model defined in step 2. Save the realizations of the desired output variables.

9) Repeat steps 6, 7 and 8 in order to obtain the desired number of simulations.

This methodology offers the advantage of integrating the user's beliefs and expert judgment in the probabilistic assessment of the potential impacts of climate change in a quantitative and objective way. In this manner, tailor-made information is obtained for the decision-maker and opens the possibility of also offering time-dependent information for decision-making concerning the potential impacts of climate variability and change that is consistent with the current state of knowledge and the subjective "expert" information available. Producing time-dependent information is crucial for planning, policy making and for building possible adaptation strategies.

\section{Methodology illustration: a case study of coffee production in Veracruz, México}

In this section, a simple illustration of this methodology is presented by means of the simple coffee production model shown in Gay et al. (2006a). The objective is to generate production and income probability distributions conditional on "expert" subjective information, and the available state of knowledge, for the average coffee producer and to estimate the risk that climate variability and change represents (present and future) for this activity. Some representative measures of risk, such as VaR (value at risk), the probability of positive (or greater than a given threshold) income values, as well as some measures of variability and central tendency of production and income and their evolution in time, are reported.

\footnotetext{
${ }^{4}$ If the input variables are correlated, MCMC simulation can be employed in order to capture the variables dependence. If variables are normally distributed, Cholesky decomposition can also be applied.
} 


\subsection{General information regarding coffee production in Veracruz}

Agriculture in Veracruz represents $7.9 \%$ of the state's GDP and employs $31.7 \%$ of the state's labor force and coffee production contributes notably to these figures. Veracruz ranks as the second largest national coffee producer. According to the 1992 Coffee Census (Consejo Mexicano del Café 1996), there are 67,000 producers and 153,000 hectares devoted to coffee production in 82 municipalities generating 300,000 permanent jobs and 30 million daily wages a year. Coffee production in the state is very labor intensive amounting to $80 \%$ of the activity's production costs (Consejo Mexicano del Café 2001).

Several national and international factors already make this activity vulnerable. $73 \%$ of coffee producers in the state are small-scale owning 2 hectares or less and the dominant type of production is "rustic" grown inside the forests in small plantations having low level of technology and a large traditional component.

Considering that in 2001 about half of the municipalities of the state were classified as under very high and high poverty levels, ${ }^{5}$ and that for most of the municipalities their sources of income depend on agriculture, and in particular on coffee production, this activity is clearly of great socioeconomic relevance for the state of Veracruz.

Since the 1990s, a combination of national and international factors has lead coffee production in Mexico to a critical situation, compromising the economic viability of this activity for a large number of producers. Currently, producers face a strong low-price competition brought about by the entrance of low-quality production to the international and national coffee markets. This has had a great impact on local producers because, even though Mexican coffee has better quality, processing companies prefer buying cheaper, low-quality coffee and improving its taste using chemicals. In recent years, national and international coffee prices have reached levels so low that a large fraction of producers are not even able to fully cover production costs. A recent study from TechnoServe (2003, in collaboration with McKinsey \& Company) reveals that the current crisis is different from all the previous coffee price crises because not only is the price volatile, but in the last 10 years the coffee industry structure has changed with the entrance of cost-efficient competitors, innovations and the increasing demand for Robusta coffee (that has lower production costs than Arabica). This means that while coffee prices will recover from their current historic low, the long term coffee price level will remain below its historical averages and will make this activity unprofitable for many producers.

The prevailing socioeconomic conditions, the limited economic and technical resources that are available to the vast majority of producers and the lack of institutional support are factors that make this activity already vulnerable and potentially limit adaptation capacities. In addition, coffee production has an important component of inertia caused mainly by following factors: increasing or decreasing production levels is a long-term decision (a coffee plant takes up to 6 years to become productive); coffee has to be harvested to maintain plantation health; market distortions (such as subsidies), make coffee supply very inelastic in the short-term to changes in coffee prices, slowing adaptation to changing market conditions (Gay et al. 2006a). As a result, although coffee prices have dramatically fallen during the past decade, coffee production in the state has remained constant or has even increased. When coffee prices fall, coffee producers partially absorb losses and are compensated to some extent by government subsidies. This has generated a great dependence on government subsidies and has increased coffee producers' vulnerability to changes in government policy - a particularly important factor in the current context of

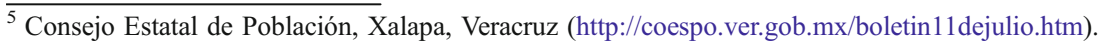


market liberalization. Not surprisingly, coffee prices and changes in government policies are the factors that coffee producers in the state identify as most threatening for this activity, while climate is perceived as a much lesser threat (Conde et al. 2007). Nevertheless, recent studies conducted in other parts of the world have shown that coffee production could be very sensitive to changes in climate variables, ${ }^{6}$ and this is also true for Veracruz (Eakin et al. 2005). Climate change could be a determinant factor for the physical and economical viability of coffee production in the state that has not been taken into account by coffee producers and government decision-makers.

\subsection{Simulation model}

For simulating coffee production in Veracruz we will adopt the coffee production model shown in Gay et al. (2006a). This is a simple, yet statistically adequate model that considers as independent variables spring precipitation, winter and summer temperatures and minimum wage paid in the state. The model adopts (Eq. 1) a linear functional form for spring precipitation and minimum wage paid in the state, and a quadratic functional form for temperature variables.

$$
\begin{aligned}
\operatorname{Pr} \text { od }_{\text {coffee }}= & -35965262+2296270\left(T_{\text {summ }}\right)-46298.67\left(T_{\text {summ }}\right)^{2}+658.01618\left(P_{\text {spr }}\right) \\
& +813976.3\left(T_{\text {win }}\right)-20318.27\left(T_{\text {win }}\right)^{2}-3549.71(\text { MINWAGE })
\end{aligned}
$$

where:

$\begin{array}{ll}T_{\text {summ }} & \text { is the average temperature during Summer. } \\ P_{\text {spr }} & \text { is the average precipitation during Spring. } \\ T_{\text {win }} & \text { is the average temperature during Winter } \\ \text { MINWAGE } & \text { is real minimum wage. }\end{array}$

The authors use elasticities as a measure of sensitivity of coffee production to changes in spring precipitation and to changes in minimum wage. These estimations reveal that production is inelastic to changes in these variables; production has a negative relation with minimum wage and is very sensitive to changes in this variable ${ }^{7}$ (for a $1 \%$ increase in minimum wage, coffee production decreases $0.37 \%$ ), while coffee production holds a positive relation with spring precipitation but of a much lower magnitude (a 1\% change in spring precipitation will produce an increase of $0.15 \%$ in coffee production). The linear functional form obtained for spring precipitation permits inferring that, for the current values of this variable in the state, the relation is positive and fairly monotonic, therefore the inflection point at which spring precipitation start to damage coffee production has not been reached (see Gay et al. 2006a).

The quadratic form in temperature variables allows capturing the non-monotonic effects that these variables have over coffee production and permit to obtain optimal temperature values for coffee production. Figure 1 illustrates the sensitivity of production to changes in temperature variables implied by Eq. 1, for fixed values of minimum wage and spring

\footnotetext{
${ }^{6}$ http://www.grida.no/db/maps/prod/level3/id 1243.htm, http://www.useu.be/Categories/Climate 795

Change/Nov0801UNEPCropyields.html, http://www.adapcc.org/download/Synthesis_Report_AdapCC_200804.pdf

${ }^{7}$ Minimum wage is employed as a proxy variable that represents labor costs/availability and accounts for about $80 \%$ of the production costs of this activity. Therefore, as expected, this variable has a great impact on coffee production.
} 
Fig. 1 Sensitivity of coffee production to changes in summer and winter temperatures

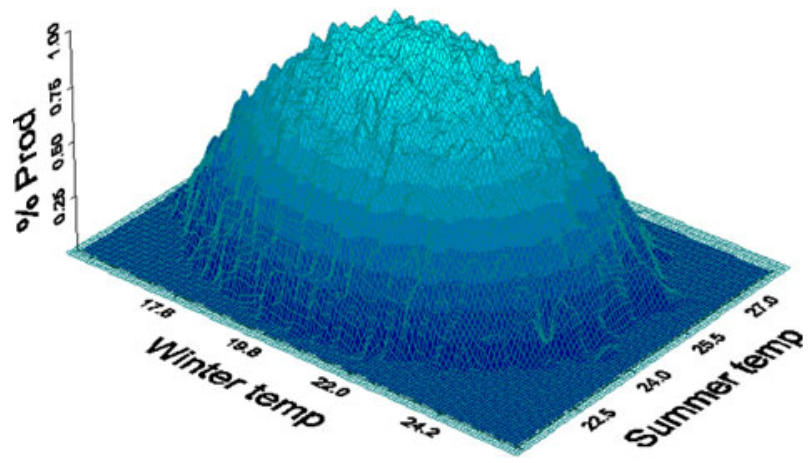

precipitation. The maximum potential production (that is a $100 \%$ value in Fig. 1) is attained when summer and winter temperatures values are optimal for coffee production $\left(24.79^{\circ} \mathrm{C}\right.$ and $20.03^{\circ} \mathrm{C}$ respectively). For any other values and combinations of summer and winter temperatures, the potential production will be smaller than $100 \%$. For example, for a summer temperature of $22.5^{\circ} \mathrm{C}$ and a winter temperature of $17.5^{\circ} \mathrm{C}$ the potential production will be about $50 \%$ smaller than for the one obtained in the case of optimal temperature values. Furthermore, if the summer temperature was of $22.5^{\circ} \mathrm{C}$ for example, no matter what the winter temperature would be, potential production would be at most $60 \%$.

Statistically adequate time series models for each variable in the coffee production model were estimated in order to approximate the data generating processes including their deterministic and stochastic components, dynamic structure, and distribution. This will permit to correctly simulate the variability shown by the series. Results show that summer temperature can be adequately described as a stationary AR(1) process around a constant, winter temperature can be represented by a deterministic trend plus a white noise process and for spring precipitation a constant plus a white noise process provides an adequate description of this series. Normality tests (Jarque-Bera) were conducted on the stochastic component of the climate variables (i.e. residuals of time series models) and the null hypothesis of normality cannot be rejected at the 5\% significance level. Therefore a normal distribution with zero mean and a specific variance for each variable will be used to represent the variability of climate variables around a deterministic component. Misspecification tests (not shown here) indicate that the models fitted to climate series are statistically adequate and therefore, provide a good approximation to their data generating process (Spanos and Mcguirk 2002).

The time series models estimated for minimum wage indicate the presence of a unit root with a structural change in 1976, and two outliers occurring in 1983 and 1988, all of them correspond to economic crises and presidential changes. Unit root processes are hardly predictable because they contain stochastic trends and their variance increases with time ( $t \sigma)$. Taking into account the time series properties of this type of processes and the time-horizon of interest for this study (2050), we consider that the observed series does not necessarily convey relevant information about its future evolution. ${ }^{8}$ This variable will be better simulated using a uniform

\footnotetext{
${ }^{8}$ Economic variables (as well as their variability) are determined by changes in fundamental factors such as technology and economic and governmental policies, for this reason, economic forecasts are seldom done for time-horizons larger than a few years. Most of economic projections for specific variables and for such large time-horizons are typically done by creating high, medium and low scenarios. A uniform distribution with a support ranging from the lowest to the highest scenario provides a continuum of reasonable possible realizations.
} 
distribution with a time-dependent support in order to describe how its uncertainty increases with time. Recall that this is a maximum entropy distribution when no additional information is included.

For calculating the income of the average producer, the total number of coffee producers will be assumed to remain constant at its current value of 67,000, each producer having 2.23 hectares devoted to this activity. Field studies conducted in the state (Gay et al. 2006b; Eakin 2003) showed that a producer faces an average cost of $\$ 8,000$ pesos or $\$ 727$ US dollars ${ }^{9}$ a year per hectare, while the average producer receives government subsidies for an amount of about $\$ 750$ pesos ( $\$ 68.2$ dollars) a year per hectare. The income of the average producer will be calculated as the gross product, minus production costs, plus government subsidies. All economic variables needed to estimate the income of the average coffee producer will be simulated using uniform distributions and are expressed in real terms.

\subsection{Climate change scenarios for 2050}

A total of 32 climate change scenarios of the mean value of each climate variable in the production model were obtained for the Veracruz region for year 2050 using the Pacific Climate Impacts Consortium Regional Analysis Tool, ${ }^{10}$ considering 7 climate models (CGCM2, HADCM3, ECHAM4, CCSRNIES, GFDLR30, NCARPCM and CSIROMK2B; note that some of them have more than one simulation for a specific emissions scenario) and the four emission scenario families (A1, A2, B1, B2).

Figure $2 \mathrm{a}, \mathrm{b}$ and $\mathrm{c}$ show the histograms of changes of spring precipitation (in $\%$ ), summer and winter mean temperatures (in ${ }^{\circ} \mathrm{C}$ ) for 2050 , respectively. Histograms are shown for descriptive purposes; it is important to note that frequencies should not be interpreted as objective probabilities (Jaynes 1957, 1962; Gay and Estrada 2010). Uncertainty in climate change scenarios is particularly large for winter temperature with a range of $3.8^{\circ} \mathrm{C}$, extending from $0.9^{\circ} \mathrm{C}$ to $4.7^{\circ} \mathrm{C}$, and for spring precipitation for which different scenarios span a range of possible values from increases of $56 \%$ to decreases of $41 \%$. These scenarios clearly illustrate the need for methodologies that can deal with these large ranges of uncertainties in order to make climate change science useful for decision making. For winter temperature the range of uncertainty in climate change scenarios is smaller but still very large, amounting to $1.5^{\circ} \mathrm{C}$.

\section{Results}

4.1 Simulation under current climate and economic conditions

A baseline simulation was carried out for approximating the current probability distributions of the state's coffee production and of the income of the average producer. This will permit to estimate some measures of the risk that the average producer faces under current conditions and comparing them with the estimations that can be obtained using different probabilistic climate change scenarios. The probability

\footnotetext{
${ }^{9}$ An exchange rate of $\$ 11$ pesos per dollar is used in this paper.

${ }^{10} \mathrm{http}: / /$ pacificclimate.org/tools/regionalanalysis/
} 
Fig. 2 a Histogram of spring precipitation changes for 2050 in Veracruz, México. b Histogram of summer temperature changes for 2050 in Veracruz, México. c Histogram of winter temperature changes for 2050 in Veracruz, México

distributions of the input variables for the simulation model were parameterized as follows:

- $\quad T_{\text {summer }} \sim \mathrm{N}(24.96,0.54)^{11}$

- $\quad T_{\text {winter }} \sim \mathrm{N}\left(21.6,{ }^{12} 0.68\right)$

- $\quad P_{\text {spring }} \sim \mathrm{N}(81.35,28.93)$

- $\quad M I N W A G E$ (daily) $\mathrm{U}(43,53)$

- Coffee price (per ton) $\sim \mathrm{U}(2,300,3,200)$

- Production costs (per hectare) $\sim \mathrm{U}(7,900,8,100)$

- Subsidy (per hectare) $\sim \mathrm{U}(700,750)^{13}$

Table 1 presents some descriptive statistics of a simulation of 10,000 realizations of coffee production in Veracruz. These statistics show that coffee production has a small variation with respect to its mean level, as shown by its coefficient of variation which is less that $12 \%$, which implies a low risk in production level. Under current conditions, coffee producers can expect a stable level of production, with a minimum state production greater than 160,000 tons. Figure 3 shows the histogram of the simulated coffee production under current conditions. The probability density function of coffee production shows that much of the probability mass is concentrated around its mean value, with a small standard deviation, but that the distribution is leptokurtic and asymmetric, having a long tail extending to lower values of coffee production. As can be seen from Fig. 3, production levels less than 300,000 tons have low probabilities of occurring.

The simulations of net income of the average producer (Table 2 and Fig. 4) show that, even if its mean value is small ( $\$ 2546.2$ pesos or $\$ 231.50$ dollars), $82.51 \%$ of the times the net income is positive and the probability of having income greater than a threshold of $\$ 5,000$ pesos ( $\$ 455$ dollars) is of $19.58 \%$. Under current climate conditions and this set of (arbitrary but reasonable) economic conditions, the average producer will seldom have losses and his maximum expected loss, as measured by the VaR (value at risk) at $99 \%$ confidence level, is of $\$ 4,832.68$ ( $\$ 439.33$ dollars). Nevertheless, it is important to notice that, given the uncertainty in prices, production costs and subsidies, the net income of the average producer is very variable as shown by its coefficient of variation $(110 \%) .{ }^{14}$ The range of the net income of the average producer amounts to $\$ 21,136.70$ (1,121.52 dollars), providing another measure of its wide variability. These descriptive statistics show that, even without climate change and with a stable coffee production, coffee producers currently face a high level of risk regarding their income.

\footnotetext{
${ }^{11}$ In this paper, the normal distribution will be defined as $\mathrm{N}(\mu, \sigma)$ and the uniform distribution as $\mathrm{U}(\mathrm{L}, \mathrm{U})$ where $\mathrm{L}$ is the lower limit and $\mathrm{U}$ the upper.

${ }^{12}$ Winter temperature shows a significant trend, so instead of using the 1961-1990 mean, the conditional mean corresponding to year 2000 was chosen.

${ }_{13}$ All economic variables are expressed in real terms.

${ }^{14}$ The variability of the net income for the average producer is not only caused by the uncertainty in the economic variables of the model. If all economic variables were taken as constants (i.e., no uncertainty), the coefficient of variation would be $53.51 \%$, considerably larger than in the case of production. The range of the net income of the average producer when all economic variables are constant is $\$ 19,993.29$.
} 
a

Spring precipitation 2050

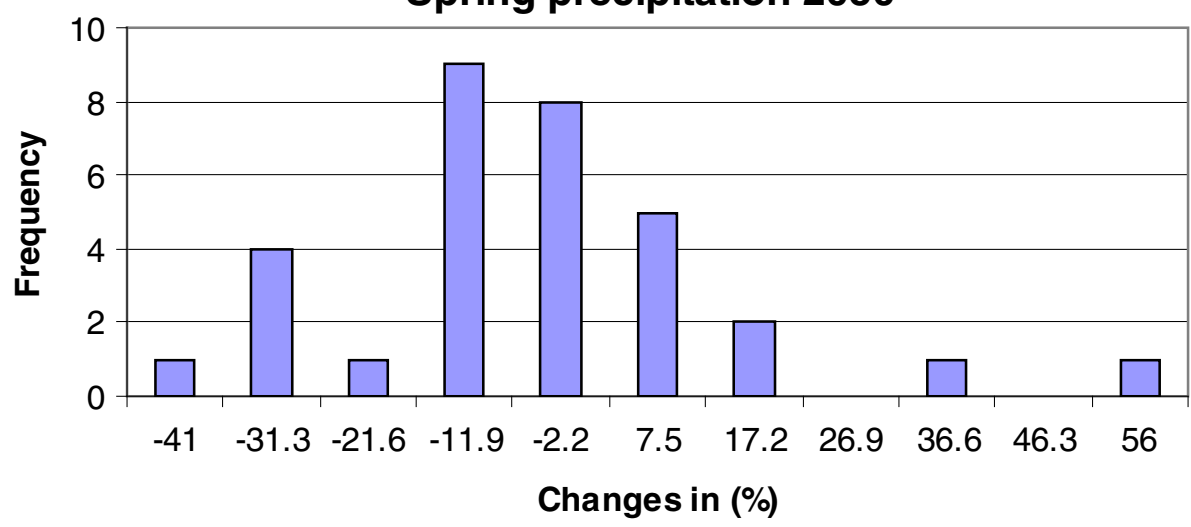

b

Summer temperature 2050

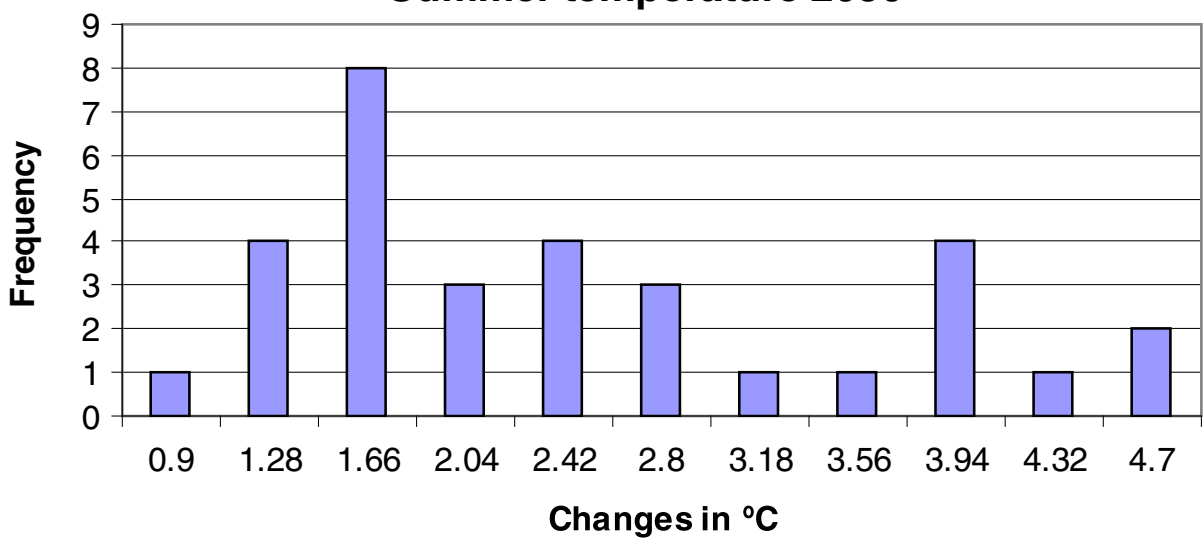

C

Winter temperature 2050

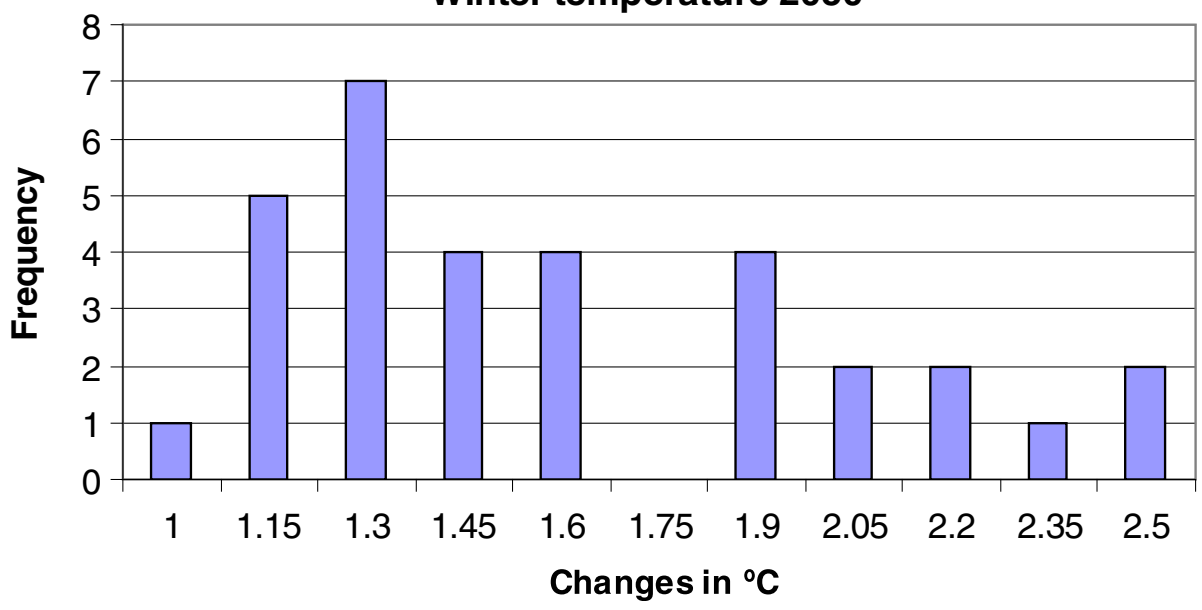


Table 1 Descriptive statistics of simulated coffee production un-

Mean

Median

S.D.

IQR

C.V.

Range

Max.

Min.

Asymmetry

Kurtosis
463,641.65

$470,523.47$

$52,214.10$

$63,573.62$

$11.26 \%$

$426,670.43$

$587,140.87$

$160,470.43$

$-0.9612$

4.7598

4.2 Dynamic simulation of state coffee production and of the average net income of the average producer under climate change conditions

Seven dynamic simulations are presented in this section, all representing different beliefs regarding future climate change. A control simulation of state coffee production and income of the average producer was carried out under the assumption of no climate change; that is climate change variables remain with the same observed distributions and moments, and uncertainty is only introduced in economic variables. This simulation could also be

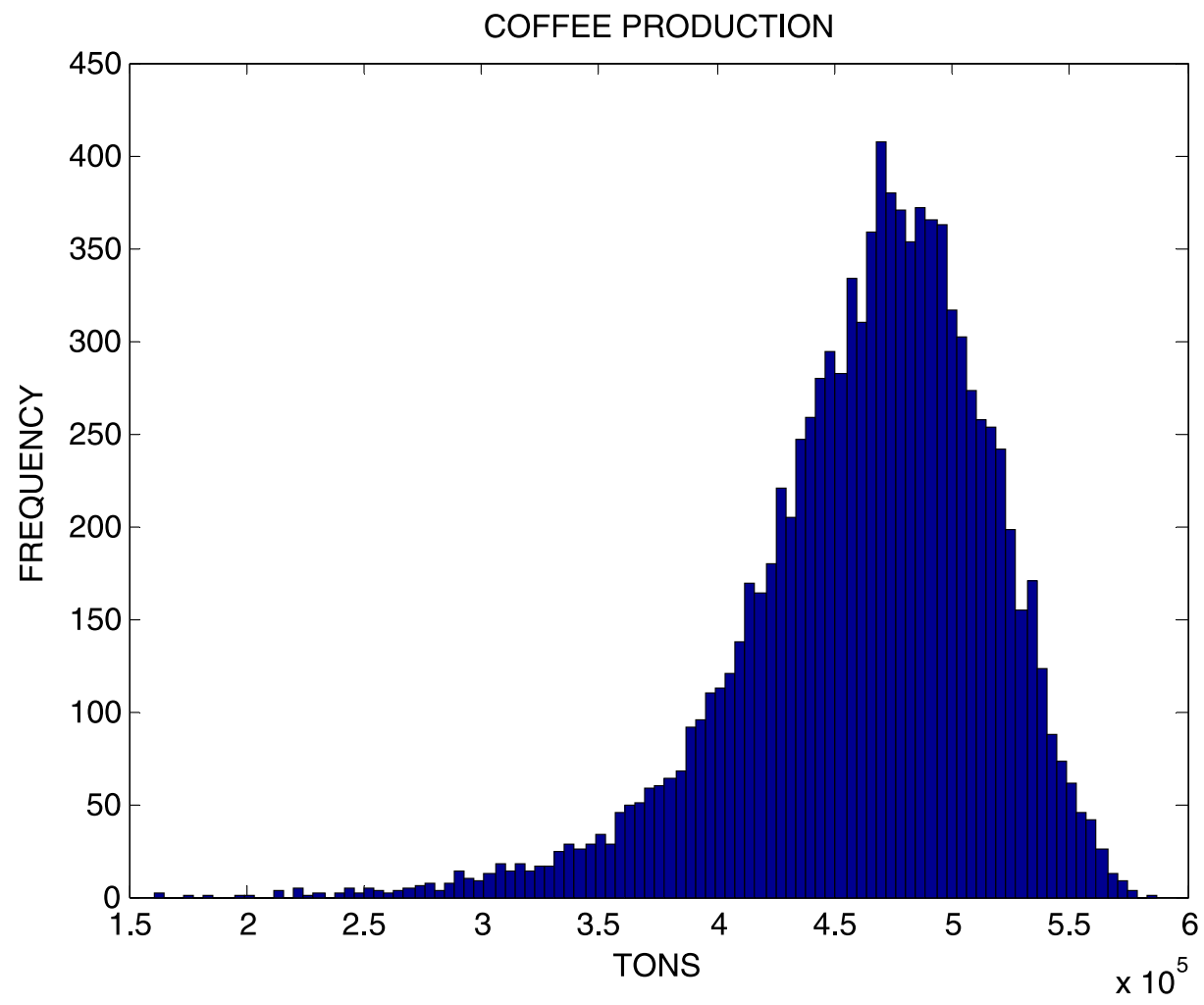

Fig. 3 Histogram of coffee production in Veracruz under current conditions (uncertainty on prices, wages, production costs and subsidies). 10,000 realizations 
Table 2 Descriptive statistics of simulated net income of the average producer under current climate conditions and the assumptions of economic variables described in the text (figures are in pesos)

\begin{tabular}{ll}
\hline Mean & $2,546.20$ \\
Median & $2,555.71$ \\
S.D. & $2,804.75$ \\
IQR & $3,835.52$ \\
C.V. & $110.15 \%$ \\
Range & $21,136.70$ \\
Max. & $10,952.10$ \\
Min. & $-10,184.87$ \\
Asymmetry & -0.2413 \\
Kurtosis & 3.1913 \\
VaR $(99 \%)$ & $-4,832.68$ \\
$\mathrm{P}(\mathrm{G} \mid \mathrm{g}>0)^{*}$ & 0.8251 \\
$\mathrm{P}(\mathrm{G} \mid \mathrm{g}>5000)^{*}$ & 0.1958 \\
\hline
\end{tabular}

interpreted as the product of the (subjective) judgment of a decision-maker/stakeholder that ignores climate change.

A second dynamic simulation of coffee production and of the income of the average producer was conducted using a single model (CGCM2) and the B2 emission scenario (Nakicenovic et al. 2000). It is important to notice that using a single emission scenario and model would imply that the analyst/decision-maker has an enormous quantity of information in order dismiss all uncertainty, and to assign zero probability to all other scenarios (the probability distribution is degenerated in one point). The main objective of these first two simulations is to compare with other simulations under uncertain climate change scenarios and to provide a rough estimation of the contribution of the uncertainty in economic variables, and of the uncertainty in both economic and climate variables to the time-dependent conditional probability distributions of coffee production and income.

The next five simulations were carried out using the Maximum Entropy methodology shown in Gay and Estrada (2010). Two of them correspond to different beliefs ranging from different degrees of "reckless" to "neutral" and up to different degrees of "cautious". Notice

Fig. 4 Histogram of the net income of the average producer in Veracruz under current climate conditions and the assumptions of economic conditions described in the text

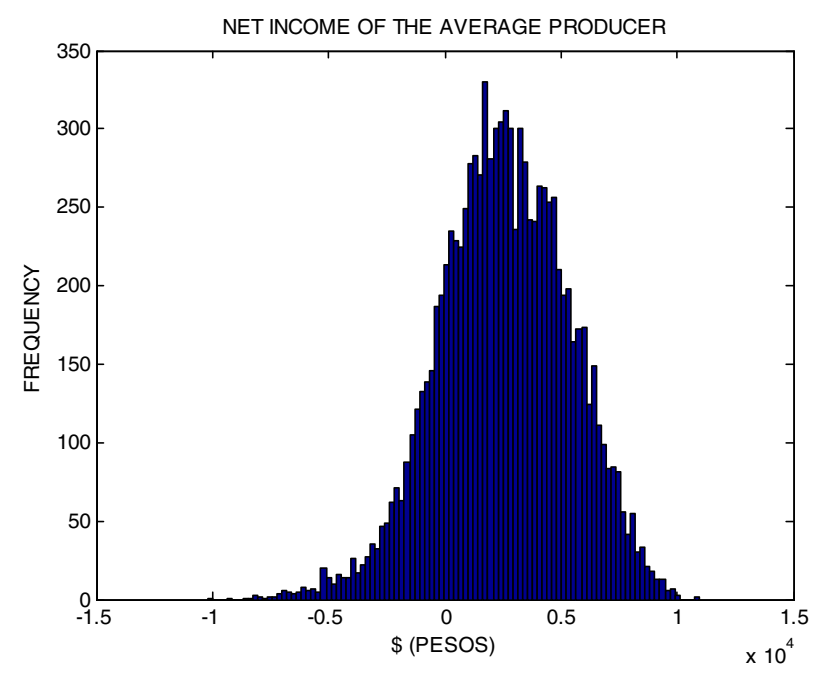


that these scenarios are tailor-made for the individual decision-maker and use his personal beliefs and uncertainty aversion.

As revealed by the information index (see Table 3 ), as the subjectively chosen mean change differs from the central value of the ensemble of scenarios, the more information the decision-maker is assuming to have, and the more uncertainty (as measured by the relative entropy) is dismissed. As an example, consider the decision-maker defined as "reckless 1", the highest levels of information and the lowest of uncertainty are assumed (the information index ranges from 0.46 in summer temperature to 0.66 in spring precipitation). This decision-maker is assuming to have a great amount of information regarding climate change in order to subjectively dismiss such a large part of the uncertainty; therefore, his probabilistic scenarios depend in great manner of his subjective (arbitrary) assumptions.

On the other hand, the choice of the mean average change of the "neutral" agent in Table 3 is the central value of the distribution of the ensemble. This mean value translates into the principle of Insufficient Reason which consists in assigning the same probability to each of the possible outcomes; this agent has no subjective reason to do it differently. The agent's uncertainty aversion does not lead him to give a greater weight to any of the known possible outcomes. In this case, the information index is zero and the relative entropy reaches its maximum value (1). The information index provides a measure of how much the probability distribution depends on the subjective information provided by the agent, ranging from zero (non informative subjective judgment), to 1 which represents a

Table 3 Average mean changes for summer and winter temperatures and spring precipitation

\begin{tabular}{|c|c|c|c|c|c|}
\hline Variable & $\begin{array}{l}\text { Average } \\
\text { mean change }\end{array}$ & $\begin{array}{l}\text { Linear reckless/ } \\
\text { cautious index }\end{array}$ & $\begin{array}{l}\text { Relative } \\
\text { entropy }\end{array}$ & $\begin{array}{l}\text { Information } \\
\text { index }\end{array}$ & Lambda $^{\mathrm{b}}$ \\
\hline \multicolumn{6}{|l|}{ Cautious 1} \\
\hline Winter temperature & $2.3^{\circ} \mathrm{C}$ & 0.73 & 0.688 & 0.312 & -4.012 \\
\hline Summer temperature & $4^{\circ} \mathrm{C}$ & 0.63 & 0.783 & 0.217 & -1.168 \\
\hline Spring precipitation & $-20 \mathrm{~mm}$ & 0.38 & 0.758 & 0.242 & 0.061 \\
\hline \multicolumn{6}{|l|}{ Cautious 2} \\
\hline Winter temperature & $1.8^{\circ} \mathrm{C}$ & 0.07 & 0.998 & 0.002 & -0.236 \\
\hline Summer temperature & $3.11^{\circ} \mathrm{C}$ & 0.16 & 0.987 & 0.013 & -0.234 \\
\hline Spring precipitation & $-5 \mathrm{~mm}$ & 0.28 & 0.961 & 0.039 & 0.020 \\
\hline \multicolumn{6}{|l|}{ Neutral } \\
\hline Winter temperature & $1.75^{\circ} \mathrm{C}$ & 0.00 & 1 & 0 & 0 \\
\hline Summer temperature & $2.80^{\circ} \mathrm{C}$ & 0.00 & 1 & 0 & 0 \\
\hline Spring precipitation & $6.10 \mathrm{~mm}$ & 0.00 & 1 & 0 & 0 \\
\hline \multicolumn{6}{|l|}{ Reckless 1} \\
\hline Winter temperature & $1.1^{\circ} \mathrm{C}$ & -0.87 & 0.50 & 0.50 & 6.930 \\
\hline Summer temperature & $1.2^{\circ} \mathrm{C}$ & -0.84 & 0.54 & 0.46 & 2.415 \\
\hline Spring precipitation & $42.93 \mathrm{~mm}$ & -0.94 & 0.34 & 0.66 & -0.209 \\
\hline \multicolumn{6}{|l|}{ Reckless 2} \\
\hline Winter temperature & $1.5^{\circ} \mathrm{C}$ & -0.33 & 0.95 & 0.055 & 1.253 \\
\hline Summer temperature & $2.3^{\circ} \mathrm{C}$ & -0.26 & 0.97 & 0.03 & 0.381 \\
\hline Spring precipitation & $14 \mathrm{~mm}$ & -0.22 & 0.98 & 0.02 & -0.014 \\
\hline
\end{tabular}

${ }^{\text {a }}$ This is also a linear measure of how far the selected average mean change is from the value (maximumminimum)/2. ${ }^{\mathrm{b}}$ Lambda is the Lagrangian Multiplier and its value is the rate of change in the objective function (entropy) as the constraint is relaxed 
degenerated distribution in one point and therefore is completely dependent on the subjective information provided by the agent.

Table 3 also shows a linear reckless/cautious (uncertainty aversion) index which provides a measure of the level of reckless or cautious attitude a particular average mean change represents. This is a linear function whose domain is the values obtained from the collection of climate change scenarios and its range is -1 to 1 . The value of minus one represents the most reckless attitude while the plus one value is the most cautious.

In the case of winter and summer temperatures, all scenarios project temperatures to increase, resulting in that coffee production would be negatively affected, and therefore entailing higher risk to coffee producers (see Eq. 1 and Fig. 1). Reckless attitude is associated with selecting mean temperature changes smaller than the central value of the distribution of the ensemble, and cautious attitude with choosing higher increments. In the case of spring precipitation, scenarios show that increments and decrements are possible. Equation 1 shows that there is a direct and linear relation between coffee production and spring precipitation, consequently reductions in the amount of spring precipitation lead to lower production levels and therefore represent higher risks for coffee producers. Reckless attitude is associated with selecting higher mean values than the central value of the ensemble.

In all cases a neutral attitude implies a zero value of the linear reckless/cautious index.

All the dynamic simulations presented in this section share the same arbitrary (but reasonable) scenarios for the evolution of economic variables. Uncertainty in economic variables is represented by a maximum entropy distribution with no additional information (that is, a uniform distribution) with a linearly increasing support which is expressed in the simulation model as follows:

- Minimum wage (daily) $\sim \mathrm{U}\left(43-\sum_{i=1}^{t} s, 53+\sum_{i=1}^{t} s\right) ; s=10 / 50$

- Coffee price (ton) $\sim \mathrm{U}\left(2,300-\sum_{i=1}^{t} p, 3,200+\sum_{i=1}^{t} p\right) ; p=1,000 / 50$

- Costs (hectare) $\sim \mathrm{U}\left(7,900-\sum_{i=1}^{t} c, 8,100+\sum_{i=1}^{t} c\right) ; c=500 / 50$

- Subsidies (hectare) $\sim \mathrm{U}\left(700-\sum_{i=1}^{t} g, 750+\sum_{i=1}^{t} g\right) ; g=100 / 50$

For each climate variables the simulation was carried out as follows:

1) A realization of the corresponding maximum entropy distribution was generated $(\Delta C){ }^{15}$

2) The mean change obtained $\Delta C$ was divided by the number of periods to be simulated (50 years) and a linear trend is constructed using this value as its slope.

3) The climate variable is generated obtaining realizations from $C_{t} \sim \mathrm{N}\left(\mu+T_{t}, \sigma\right)$ where $\mathrm{T}$ is the linear trend generated in step 2), $\mu$ and $\sigma$ are the current mean value and standard deviation of the observed variable. In the case of spring precipitation the normal distribution was truncated in zero to avoid the possible occurrence of negative values.

4) For each variable these three steps were repeated 10,000 times.

Tables 4 and 5 show, as an example, some of the risk measures that can be obtained by means of this methodology. It is important to notice that, given that this methodology provides the conditional distributions of coffee production and income of the average producer, a wide range of risk measures can be produced. The relevant risk measures, and their thresholds, are to be defined according to the informational needs of the agent/stakeholder in order to

${ }_{15}$ The first two dynamic simulations (control and the one based in the CGCM2-B2 scenario) imply degenerated probability distributions, so for these simulations $\Delta C$ are constant values. 
Table 4 Risk measures obtained for state coffee production

a)

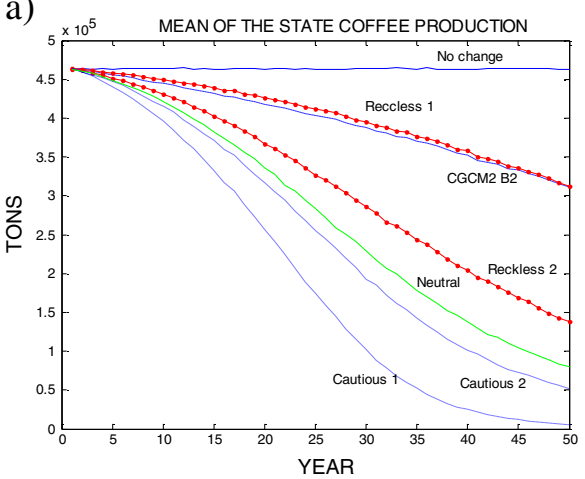

c)

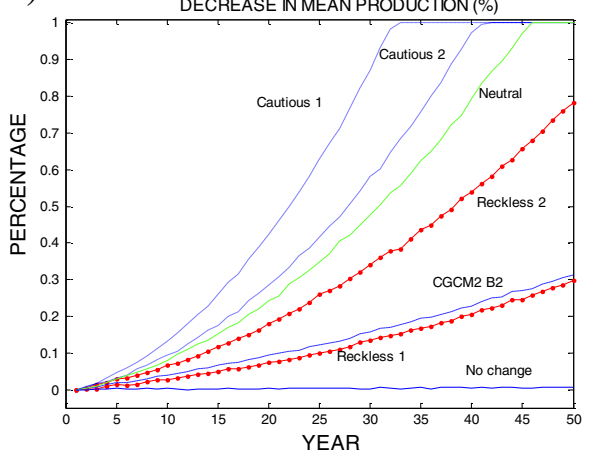

e)

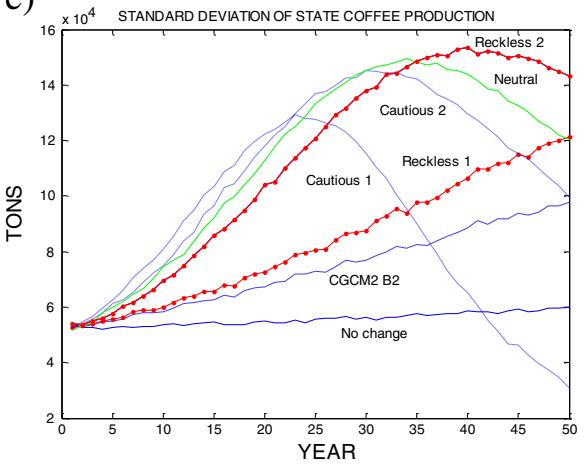

b)

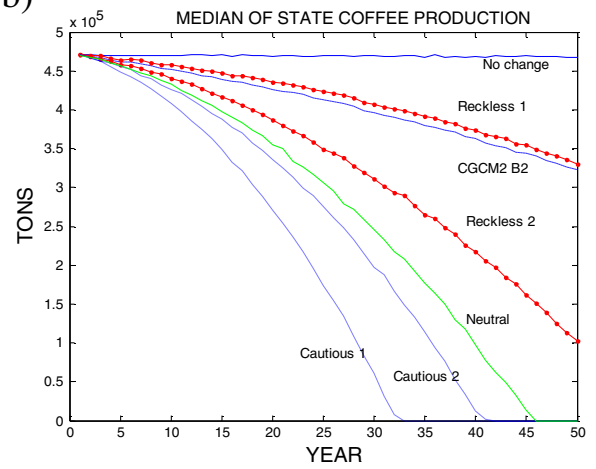

d)

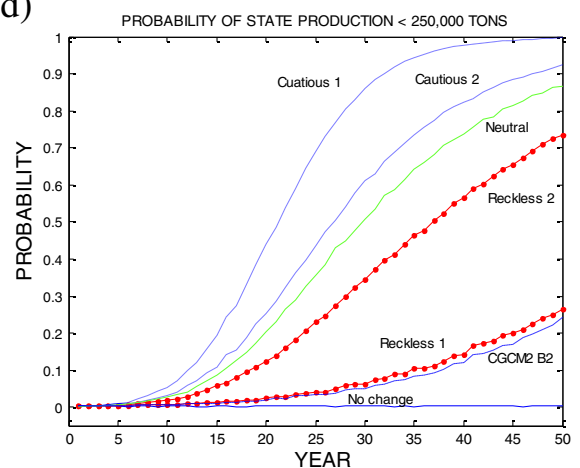

f)

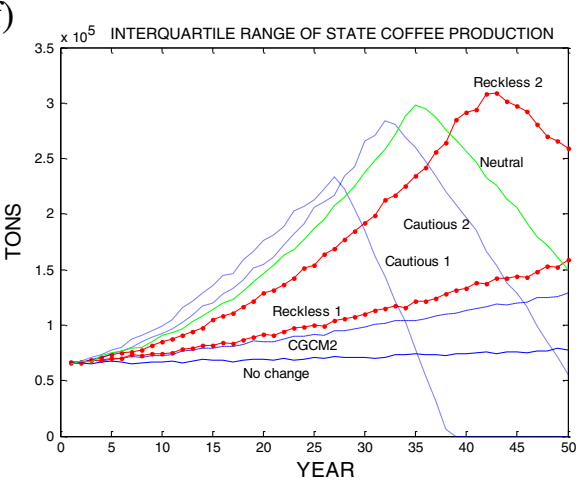

effectively aid in the planning and decision-making processes. These can include risk measures such as mean, variance and VaR which are typical for "investment" analysis, or more sophisticated ones such as median, interquartile range and estimations of the probability of reaching a predetermined threshold value. The idea is that going over each of these thresholds would trigger an action that has to be defined also by the stakeholder, which, as a whole, would produce a time-line for strategic planning. 
Table 5 Risk measures obtained for income of the average coffee producer in Veracruz
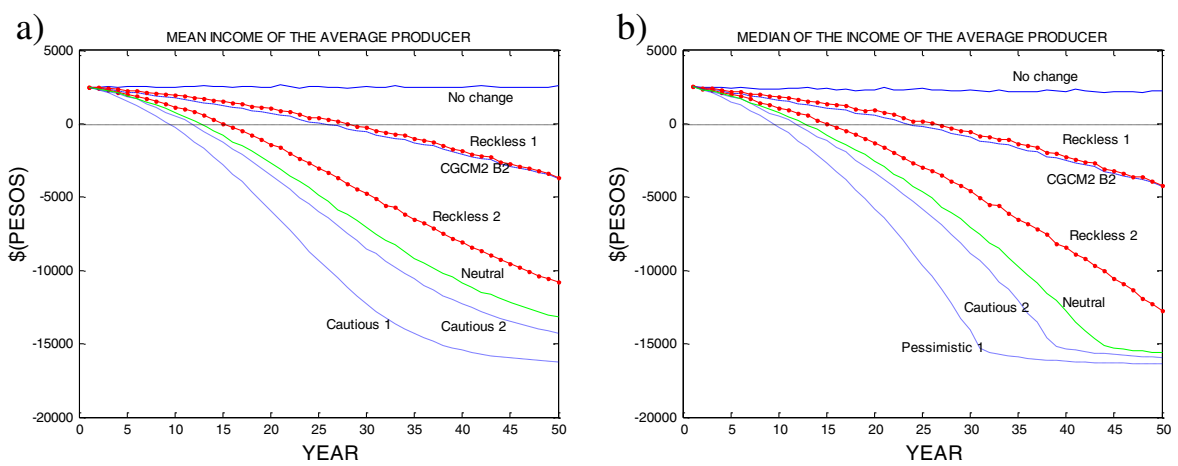

c)

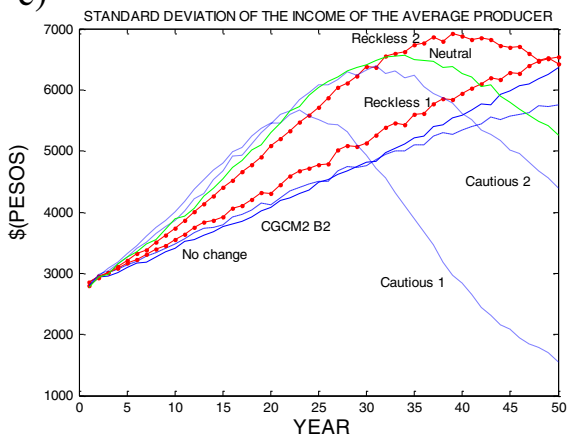

d)
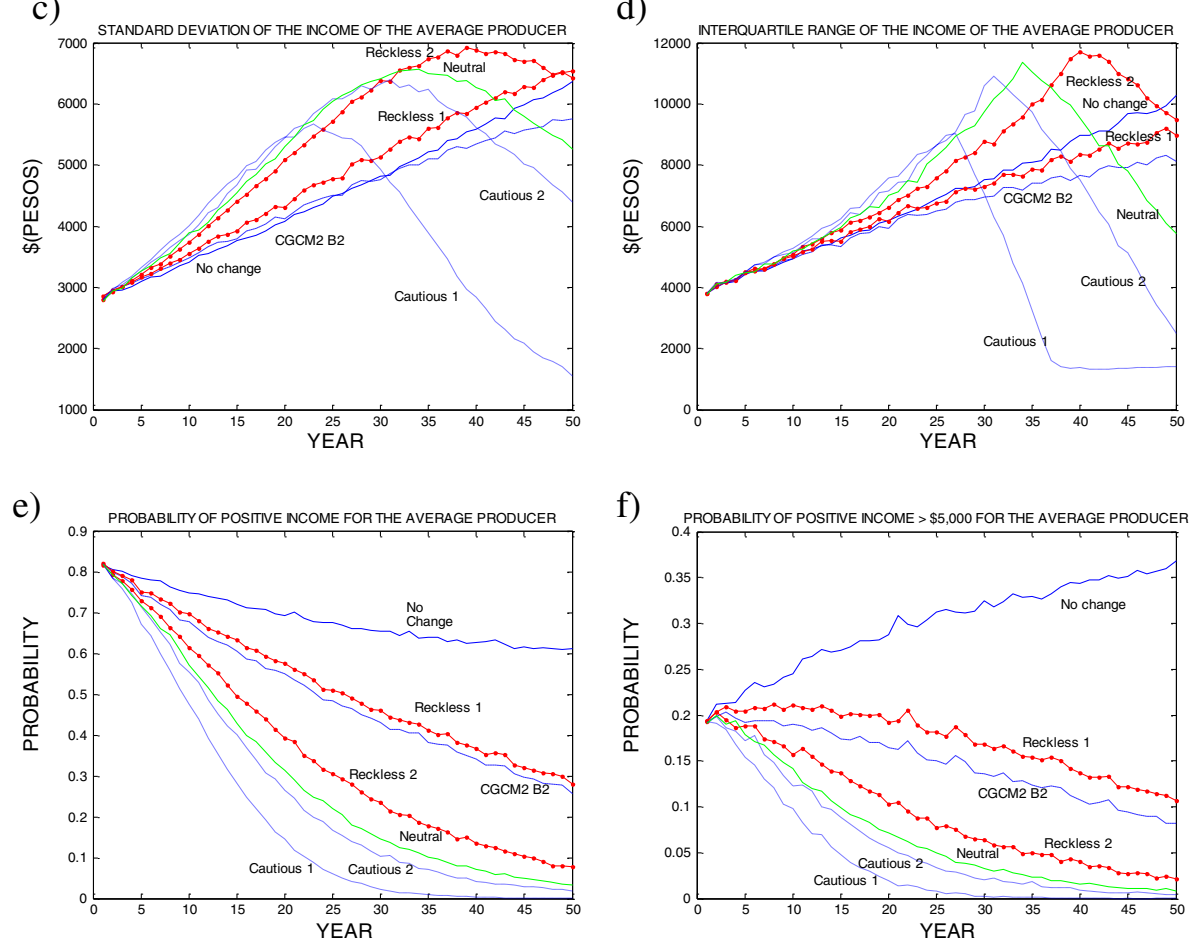

g)
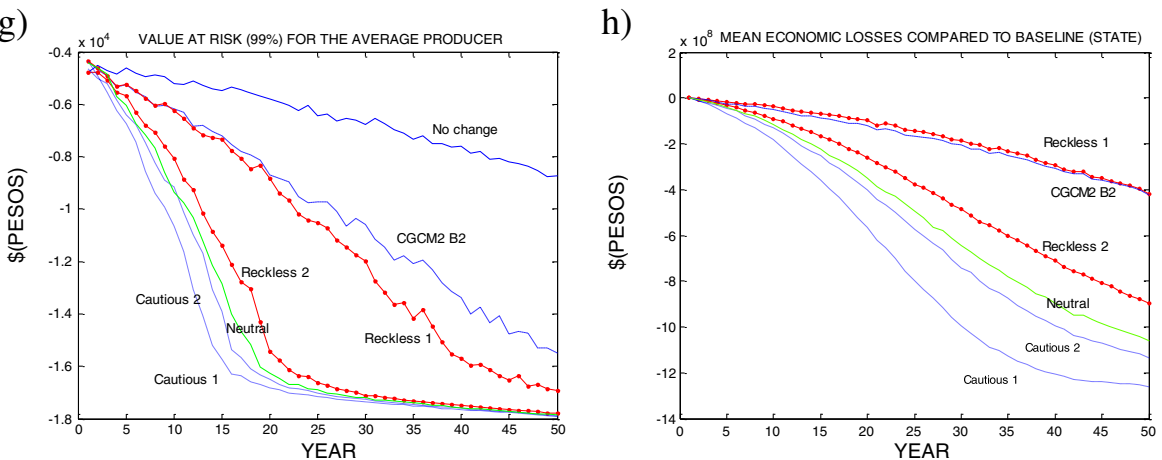
For example, assume that the relevant risk measures and thresholds for two particular decision-makers (government agencies, for example) are a 10 and a $30 \%$ of decrease in state production, 10 and $50 \%$ probability of state production being less than 250,000 tons, a standard deviation of state coffee production of 60,000 and 80,000 tons, 70 and $60 \%$ probability of positive net income for the average producer, and a value for the largest expected loss for the average producer (as measured by the VaR) of $-\$ 10,000$ pesos $(\$ 909$ dollars). Also assume that each of these decision-makers has different beliefs (reckless and cautious) about the evolution of climate variables. ${ }^{16}$ Each of these thresholds would trigger some specific action defined by the decision-maker in order to adapt. This methodology provides an estimation of the date on which each of these thresholds will occur according to the subjective beliefs of the decision-maker and therefore permits planning on which actions should have to be implemented for these dates.

This is a sequential process: it is important to have in mind that new simulations should be carried out as new information becomes available. In the light of this new information, beliefs are to be revised and updated as a clearer picture of climate change and its impacts can be obtained. The relevance of the proposed risk measures, thresholds and actions should also be regularly evaluated.

Tables 4 and 5 show that for the "cautious" decision-maker (line labeled as Cautious 2) the first threshold to be reached is 60,000 tons of standard deviation in state coffee production on the fifth year, followed by the probability of the average producer having a positive income of $70 \%$ on the sixth year and $60 \%$ in the ninth year. On the 11 th year, mean state coffee production reaches the thresholds of a $10 \%$ decrease and a standard deviation of 80,000 tons, while the Value at Risk $(99 \%)$ for the average producer also reaches its predefined threshold of $-\$ 10,000$ pesos ( $\$ 909$ dollars). The probability of state coffee production being smaller than 250,000 tons reaches the pre-defined thresholds of $10 \%$ and $50 \%$ on the 14 th and 26 th years, respectively, while the reduction of $30 \%$ in mean state coffee production occurs on the 21 st year.

The uncertainty in production (as measured by the standard deviation) generates greater variability (and uncertainty) in the expected income of the average producer. Therefore, lower probabilities of positive income for the average producer follow shortly as well as increments in the value of the VaR. It is also interesting to notice, that for this type of belief, the rate of decrease in mean state coffee production quickly accelerates as a function of time, similar to the case of the probability of coffee production being less than 250,000 tons where the increment of this probability accelerates as a function of time.

For the "reckless" decision-maker (line labeled as Reckless 2) the timing of occurrence of the pre-defined critical thresholds is very different. The first thresholds to be reached are also the 60,000 tons of standard deviation in state coffee production the 10th year, followed on the 11 th year by reaching a $70 \%$ probability of having a positive income for the average producer, and a $60 \%$ probability in this same risk measure by the 18 th year. On year 23 , the standard deviation of state coffee production reaches the second pre-defined threshold, and a year later the threshold for the VaR occurs. The second threshold of standard deviation in coffee production occurs on the 23 rd year, followed by the thresholds of $10 \%$ in the mean state coffee production in the 25 th year, $10 \%$ probability of having state production below 250,000 tons in year 35, and a 30\% reduction in mean state coffee production in year 49 . The threshold of $50 \%$ probability of having state production below 250,000 tons never is reached. Notice that for this type of belief, the rate of change of the risk measures is much smaller than for the case of cautious beliefs, most of them being almost linear functions of time.

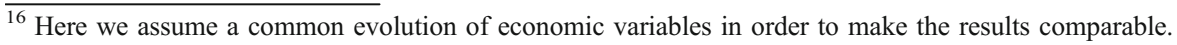


Tables 4 and 5 also show how production would develop if no climate change occurs, and therefore provides a baseline for inferring the costs of climate change in this activity. As can be seen from this table, when no climate change is considered, the economic scenario chosen for all simulations implies a stable production, very similar to the production that can be achieved under current conditions, with a very small increase in variability for the last years of the simulation. The mean/median of the income of the average producer also remains fairly constant, while its variability increases almost linearly, reflecting the uncertainty in prices and production costs. This no climate change scenario produces a slow decrease in the probability of positive income for the average producer, while also the probabilities of having an income increase up to more than a $35 \%$ (this is a direct result of uncertainty in prices and costs). Under this scenario, the maximum expected loss (VaR) for the average producer never reaches - $\$ 10,000$ pesos ( $\$ 909$ dollars). Panel $\mathrm{h}$ of Table 5 presents the estimations of the mean economic losses for this activity in Veracruz. The total accumulated present value of the losses up to 2050 are in the range of 3,000 to 14,000 millions of pesos (from 273 to 1,273 million dollars), depending on the different beliefs assumed by the decision-maker, using an annual discount rate of $3 \%$. These losses represent from 3 to 14 times the current annual value of the state coffee production.

Climate change, through its direct and indirect effects, has two important types of costs: a reduction of production and of the associated income of the producer, and an increase in the financial and planning costs caused by a rise in the risk of this activity due to the large uncertainty in climate scenarios.

Lastly, it is also shown in Tables 4 and 5 a simulation (labeled CGCM2 B2) using just one model (CGCM2) and one emission scenario (B2). This simulation represents the impacts assuming degenerated probability distributions in the values obtained by this run; that is, as if there was no uncertainty in the climate change projections. Although the results of this simulation are similar in the case of central tendency measures to those of the simulation labeled as Reckless 1, there are some fundamental differences. First of all, the CGCM2 B2 discards all other possible climate change scenarios (outcomes), it assumes to have all the information (no uncertainty, zero entropy) representing an information index value of 1, while the Reckless 1 simulation uses all possible outcomes, and therefore has an information index value ranging from 0.46 to 0.66 ; results from the CGCM2B2 simulation are completely dependent on the subjective information (beliefs) of the decision-maker and does not reflect all the state of knowledge regarding climate change scenarios for the region. The CGCM2B2 provides a false "confidence" in estimations as revealed by its low range of uncertainty as measured by all dispersion estimates, and necessarily provides a poor estimation of risk (because it is based on a single realization) entailing greater dangers for decision-making. This is to reduce uncertainty in an unjustifiable manner: trading uncertainty by ignorance (Schneider 2003). Furthermore, to consider a single outcome (a model and an emission scenario) without the context of the range of scenarios cannot tell the decision-maker if the scenario he chose represents a reckless, cautious (and by how much) or neutral.

\section{Conclusions}

One of the main conclusions of this paper is that, given that objective probabilities in climate change scenarios are not attainable, no "true" impact scenario can be constructed even in a probabilistic framework (see Gay and Estrada 2010). Uncertainty must therefore be preserved as much as possible in order not to discard in an unjustifiable manner any available knowledge (outcome) to be used for constructing impact scenarios. 
Some of the drawbacks of the methods used for integrating uncertainty in impact assessment are discussed. One of the major pitfalls of the commonly used frequentist approach is that the resulting probability distributions are presented as "objective" facts, when it should be clearly stated that they are all subjective representations of beliefs (Gay and Estrada 2010). It is argued that subjective beliefs should be brought forward, be clearly stated and that probability distributions should be a meaningful expression of the decisionmaker beliefs and not some impersonal, one-size fits all, statistically inadequate device.

This paper presents a new approach for generating climate change impact scenarios that integrates uncertainty and variability, as well as the agent's beliefs or expert judgment, in order to produce tailor-made information for supporting decision-making and planning. It is also shown that time-dependent impact probability distributions (conditional on the available state of knowledge and subjective beliefs) can be constructed and that a great variety of risk measures can be obtained. These risk measures should be aimed to fulfill the information needs of the decision-maker.

The methodology is based in the Maximum Entropy Principle as presented in Gay and Estrada (2010), time series modeling for approximating the true data generating process and Monte Carlo simulation. The proposed methodology for constructing probabilistic climate change scenarios can produce estimates which have desirable properties such as: they are the least biased estimate possible on the available information; maximize the uncertainty (entropy) subject to the partial information that is given; the maximum entropy distribution assigns a positive probability to every event that is not excluded by the given information; no quantifiable possibility is ignored; the probabilities obtained in this manner are the best predictions possible with the state of knowledge and subjective information that is available.

The methodology is illustrated with a case study of coffee production in Veracruz (see Gay et al. 2006a). Seven simulations are presented using arbitrary, but reasonable, assumptions for the economic variables and various maximum entropy probability distributions which represent different subjective beliefs of different possible decision-makers. The time evolution of several possible risk measures and the date on which they would reach arbitrary thresholds are presented.

The costs of climate change for coffee production are estimated to have a present value in the range of approximately 3,000 to 14,000 million pesos (from 273 to 1,273 million dollars), depending on the different beliefs assumed by the decision-maker. Although it is important to notice that no adaptation activity is included and the number of producers is fixed (there are neither entries nor exits of the activity).

It is also argued that climate change, through its direct and indirect effects, has two important types of costs: a reduction of production and of the associated income of the producer and; an increase in the financial and planning costs caused by a rise in the risk of this activity due to the large uncertainty in climate scenarios.

Open Access This article is distributed under the terms of the Creative Commons Attribution Noncommercial License which permits any noncommercial use, distribution, and reproduction in any medium, provided the original author(s) and source are credited.

\section{References}

Ahmad QK, Warrick RA (eds.) (2001) Methods and tools. In: Climate change 2001: impacts, adaptation, and vulnerability. contribution of working group ii to the third assessment report of the intergovernmental panel on climate change. Cambridge: Cambridge University Press 
Allen MR (2003) Possible or probable? Nature 425:242

Andreou A, Spanos A (2003) Statistical adequacy and the testing of trend versus difference stationary. Econ Rev 22:217-237

Carter TR, Jones RN, Lu X, Bhadwal S, Conde C , Mearns LO, O’Neill BC, Rounsevell MDA, Zurek MB (2007) New assessment methods and the characterization of future conditions. Climate change 2007: impacts, adaptation and vulnerability. Contribution of working group II to the fourth assessment report of the intergovernmental panel on climate change, ML Parry, Canziani OF, Palutikof JP, van der Linden PJ, Hanson CE (eds) Cambridge University Press, Cambridge, UK, 133-171

Christensen JH, Hewitson B, Busuioc A, Chen A, Gao X, Held I, Jones R, Kolli RK, Kwon W-T, Laprise R, Magaña Rueda V, Mearns L, Menéndez CG, Räisänen J, Rinke A, Sarr A, Whetton P (2007) Regional climate projections. In: Solomon S, Qin D, Manning M, Chen Z, Marquis M, Averyt KB, Tignor M, Miller HL (eds) Climate change 2007: the physical science basis. Contribution of working group I to the fourth assessment report of the intergovernmental panel on climate change. Cambridge University Press, Cambridge and New York

Conde C, Vinocur M, Gay C, Seiler R, Estrada F (2007) Climatic threat spaces in Mexico and Argentina. In: Leary N, Conde C, Kulkarni J, Nyong A, Pulhin J (eds) Climate change and vulnerability. Earthscan, TWAS, START. 279-306

Consejo Mexicano del Café-Secretaría de Agricultura, Ganadería y Desarrollo Rural: (1996) México Cafetalero Estadísticas Básicas. México

Consejo Mexicano del Café-Secretaría de Agricultura, Ganadería y Desarrollo Rural: (2001) Perspectivas de la cafeticultura en México. Available at www.cmcafe.org.mx, México

Gobierno de la República de Argentina (2008) 2da Comunicación Nacional de la República Argentina a la Convención Marco de las Naciones Unidas sobre Cambio Climático. Available at: http://unfccc.int/ resource/docs/natc/argnc2s.pdf

Secretaría de Medio Ambiente y Recursos Naturales/Instituto Nacional de Ecología (2006) México Tercera Comunicación Nacional ante la Convención Marco de las Naciones Unidas sobre el Cambio Climático. Available at: http://unfccc.int/resource/docs/natc/mexnc3.pdf

Eakin, H (2003) 'Workshop report. Integrated assessment of social vulnerability and adaptation to climate variability and change among farmers in Mexico and Argentina', Project supported by UNDP-GEF, 2002-2004

Eakin H, Tucker CM, Castellanos E (2005) Market shocks and climate variability: the coffee crisis in Mexico, Guatemala, and Honduras. Mt Res Dev 25(4):304-309

Ellsberg D (1961) Risk, ambiguity, and the savage axioms. Q J Econ 75(4):643-669

Estrada F, Gay C, Sánchez A (2010) Reply to "does temperature contain a stochastic trend? Evaluating conflicting statistical results by Kaufmann et al.”. Clim Chang 101:407-414. doi:10.1007/s10584-010-9928-0

Gay C (PI), Seiler R, Conde C, Eakin H, Vinocur M et al (2006b) Final report: "Integrated assessment of social vulnerability and adaptation to climate variability and change among farmers in Mexico and Argentina". $239 \mathrm{pp}$ [available at http://aiaccproject.org/Final\%20Reports/Final\%20Reports/FinalRept_AIACC_LA29.pdf]

Gay C, Estrada F (2010) Objective probabilities about future climate are a matter of opinion. Clim Chang 99 $(1-2): 27-46$

Gay C, Estrada F, Conde C, Bravo JL (2006c) Uso de Métodos de Monte Carlo para la Evaluación de la Vulnerabilidad y Riesgo ante Condiciones Actuales Bajo y Bajo Cambio Climático. V. Congreso de la Asociación Española de Climatología. Zaragoza, España, pp 18-21 de septiembre, 2006, pp 762-770

Gay C, Estrada F, Conde C, Eakin H, Villers L (2006a) Potential impacts of climate change on agriculture: a case of study of coffee production in Veracruz, México. Climatic Change. 79(3-4): 259-288. Springer Netherlands

Gay C, Estrada F, Conde C (2007) Some implications of time series analysis for describing climatologic conditions and for forecasting. An illustrative case: Veracruz, México. Atmosfera 20(2):147-170

Gay C, Estrada F, Sánchez A (2009) Global and hemispheric temperatures revisited. Clim Chang 94(34):333-349

Government of Japan (2006) Japan's Fourth National Communication Under the United Nations Framework Convention on Climate Change. Available at: http://unfccc.int/resource/docs/natc/japnc4.pdf

Government of the Federal Republic of Germany (2006) Fourth National Report by the Government of the Federal Republic of Germany. Available at: http://unfccc.int/resource/docs/natc/gernc4.pdf

Grübler A, Nakicenovic N (2001) Identifying dangers in an uncertain climate. Nature 412:15

Hulme M, Wigley TML, Brown EM, Raper SCB, Centella A, Smith S, Chipanshi AC (2000) Using climate scenario generator for vulnerability and adaptation assessment: MAGICC and SCENGEN. Version 2.4 Workbook, Climate Research Unit, Norwich, UK, 52 pp

IPCC, WGI (Intergovernmental Panel on Climate Change Working Group I) (2007) Summary for policymakers. In: Solomon S, Qin D, Manning M, Chen Z, Marquis M, Averyt KB, Tignor M, Miller 
HL (eds) Climate change 2007: the physical science basis. Contribution of working group I to the fourth assessment report of the intergovernmental panel on climate change. Cambridge University Press, Cambridge and New York

IPCC, WGII (Intergovernmental Panel on Climate Change Working Group II) (2007) Summary for policymakers. In: Parry ML, Canziani OF, Palutikof JP, van der Linden PJ, Hanson CE (eds) Climate change 2007: impacts, adaptation and vulnerability. Contribution of working group ii to the fourth assessment report of the intergovernmental panel on climate change. Cambridge University Press, Cambridge, pp 7-22

IPCC-TGICA (2007) General guidelines on the use of scenario data for climate impact and adaptation assessment. Version 2. Prepared by T.R. Carter on behalf of the Intergovernmental Panel on Climate Change, Task Group on Data and Scenario Support for Impact and Climate Assessment, 66 pp

IPCC-TGICIA (Task Group on Climate Scenarios for Impacts Assessments) (1999) Guidelines on the use of Scenario data for climate impact and adaptation assessment. Version 1. Prepared by T.R. Carter, M. Hulme and M. Lal, Intergovernmental Panel on Climate Change, Task Group on Scenarios for Climate Impact Assessment, $69 \mathrm{pp}$

Jaynes ET (1957) Information theory and statistical mechanics. The Physical Review 106(4):620-630

Jaynes ET (1962) In: Ford KW (ed) Information theory and statistical mechanics. Brandeis University summer institute lectures in theoretical physics, vol. 3, 181-218

Jones RN (2000) Managing uncertainty in climate change projections - issues for impact assessment. Clim Chang 45:403-419

Jones RN (2001) An environmental risk assessment/management framework for climate change impact assessments. Nat Hazard 23:197-230

Kelsey D, Eichberger J (2009) Ambiguity. In: Pattanaik A, Puppes (eds) Survey paper in Handbook of Rational and Social Choice. OUP

Meehl GA, Stocker TF, Collins WD, Friedlingstein P, Gaye AT, Gregory JM, Kitoh A, Knutti R, Murphy JM, Noda A, Raper SCB, Watterson IG, Weaver AJ, Zhao Z-C (2007) Global climate projections. In: Solomon S, Qin D, Manning M, Chen Z, Marquis M, Averyt KB, Tignor M, Miller HL (eds) Climate change 2007: the physical science basis. Contribution of working group $i$ to the fourth assessment report of the intergovernmental panel on climate change. Cambridge University Press, Cambridge and New York

Moss RH, Schneider SH (2000) Uncertainties in the IPCC TAR: recommendations to lead authors for more consistent assessment and reporting. In: Pachauri R, Taniguchi T, Tanaka K (eds) Guidance papers on the cross cutting issues of the third assessment report of the IPCC. World Meteorological Organization, Geneva, pp 33-51

Mukerji S (2000) A survey of some applications of the idea of ambiguity aversion in economics. Int J Approx Reason 24:221-234

Nakicenovic N, Alcamo J, Davis G, de Vries B, Fenhann J, Gaffin S, Gregory K, Grübler A, Jung TY, Kram T, La Rovere EL, Michaelis L, Mori S, Morita T, Pepper W, Pitcher H, Price L, Riahi K, Roehrl A, Rogner H-H, Sankovski A, Schlesinger M, Shukla P, Smith S, Swart R, van Rooijen S, Victor N, Dadi Z (2000) Special report on emissions scenarios: a special report of working group iii of the intergovernmental panel on climate change. Cambridge University Press, Cambridge, 599 pp

Nawaz NR, Adeloye AJ (2006) Monte Carlo assessment of sampling uncertainty of climate change impacts on water resources yield in Yorkshire, England. Clim Change 78(2-4):257-292

New M, Hulme M (2000) Representing uncertainty in climate change scenarios: a Monte Carlo approach. Integr Assess 1:203-213

Pittock AB, Jones RN, Mitchell CD (2001) Probabilities will help us plan for climate change. Nature 413:249

Preston BL (2006) Risk-based reanalysis of the effects of climate change on U.S. cold-water habitat. Clim Change 76(1-2):91-119

Schneider SH (2001) What is 'Dangerous' climate change? Nature 411:17-19

Schneider SH (2002) Can we estimate the likelihood of climatic changes at 2100? An editorial comment. Clim Change Vol. 52, No. 4

Schneider SH (2003) Imaginable surprise, In: Potter TD (ed) Handbook of weather, climate, and water, John Wiley and Sons

UNFCCC Secretariat (2008a) Compendium on methods and tools to evaluate impacts of, and vulnerability to, climate change. $228 \mathrm{pp}$

Spanos A, Mcguirk A (2002) Where do statistical models come from? The problem of specification uncertainty in empirical modeling. (Virginia Tech working paper, 2002); (available at http://www.econ. ucy.ac.cy/seminars/Spanos.pdf).

Stein A, Segal U (2006) Ambiguity aversion and the criminal process. Notre Dame Law Review 81 (2006). Available at: http://works.bepress.com/alex_stein/6

Tebaldi C, Lobell DB (2008) Towards probabilistic projections of climate change impacts on global crop yields. Geophys Res Lett 35:L08705. doi:10.1029/2008GL033423 
TechnoServe (2003) Developing solutions to challenges in the coffee industry, http://www.technoserve.org/ McKinseyAnalysis.pdf

Titus JG, Narayanan V (1996) The risk of sea level rise. Clim Change 33:151-212

Toth FL, Bruckner T, Füssel H-M, Leimbach M, Petschel-Held G (2003a) Integrated assessment of long-term climate policies. Part 1. Model presentation. Clim Chang 56:37-56

Toth FL, Bruckner T, Füssel H-M, Leimbach M, Petschel-Held G (2003b) Integrated assessment of longterm climate policies. Part 2. Model results and uncertainty analysis. Clim Chang 56:57-72

UNDP (2005) Adaptation policy frameworks for climate change: developing strategies, policies and measures. Lim B, Spanger-Siegfried E, Burton I, Malone E, Huq S (eds) Cambridge University Press, Cambridge and New York, $258 \mathrm{pp}$

UNFCCC (2008b) Handbook on vulnerability and adaptation assessment. http://unfccc.int/resource/ userman_nc.pdf (1/10/2008).

Wakker P (2001) Testing and characterizing properties of nonadditive measures through violations of the sure thing principle. Econometrica 69:1039-1060

Wigley TML (1994) MAGICC (Model for the Assessment of Greenhouse-gas Induced Climate Change): user's guide and scientific reference manual. National Centre for Atmospheric Research, Boulder

Wigley T (2003) MAGICC/SCENGEN 4.1: technical manual 14 pp., and MAGICC/SCENGEN 4.1: User Manual. Boulder, CO, USA. 24 pp

Wigley TML (2008) MAGICC version 5.3 (Model for the Assessment of Greenhouse-gas Induced Climate Change): user's guide and scientific reference manual. National Centre for Atmospheric Research, Boulder

Willows R, Connell R (2003) Climate adaptation: risk, uncertainty, and decisionmaking. UK Climate Impacts Programme, Oxford

WMO (1983) Guide to climatological practices, Second Edition. Secretariat of the World Meteorological Organization. Geneva Switzerland. (http:/www.wmo.ch/web/wcp/ccl/GuideHome/html/wmo100.html)

Yohe GW, Schlesinger ME (1998) Sea-level change: the expected economic cost of protection or abandonment in the United States. Clim Chang 38:337-342 